\title{
The benefit of deep processing and high educational level for verbal learning in young and middle-aged adults
}

\author{
Willemien A. Meijer ${ }^{1}$, Pascal W.M. Van Gerven ${ }^{2}$, Renate H.M. de Groot ${ }^{1}$, Martin P.J. Van Boxtel ${ }^{1,2}$, \\ and Jelle Jolles ${ }^{1,2}$ \\ ${ }^{1}$ Faculty of Medicine, Department of Psychiatry and Neuropsychology, ${ }^{2}$ Faculty of Psychology, Department \\ of Neurocognition, Maastricht University, Maastricht, The Netherlands
}

\begin{abstract}
Background and aims: The aim of the present study was to examine whether deeper processing of words during encoding in middle-aged adults leads to a smaller increase in word-learning performance and a smaller decrease in retrieval effort than in young adults. It was also assessed whether high education attenuates age-related differences in performance. Methods: Accuracy of recall and recognition, and reaction times of recognition, after performing incidental and intentional learning tasks were compared between 40 young (25-35) and 40 middleaged (50-60) adults with low and high educational levels. Results: Age differences in recall increased with depth of processing, whereas age differences in accuracy and reaction times of recognition did not differ across levels. High education does not moderate agerelated differences in performance. Conclusions: These findings suggest a smaller benefit of deep processing in middle age, when no retrieval cues are available.
\end{abstract}

(Aging Clin Exp Res 2007; 19: 372-380)

${ }^{\circ}$ 2007, Editrice Kurtis

\section{INTRODUCTION}

In the abundance of studies on age-related cognitive differences, comparisons have been made between relatively young adults (usually in their 20s), and older adults (usually older than 65). Although the age range between 30 and 60 has often been disregarded, it may be of particular interest, because the first manifestations of age-related cognitive change (1-4) and cognitive complaints (5) can already be seen from age 40 . Previous studies have not been able to establish a relation between subjective cognitive complaints and poor cognitive performance in middle age $(6,7)$. One possible explanation for this discrepancy may involve the psychological construct "effort". Middleaged adults may need to invest more cognitive effort to achieve the same performance as young adults, especially in resource-demanding situations, e.g., in professional life. Indeed, cognitive challenges at midlife are generally high, and consist of work and family environments requiring particular skills, such as organizing, planning, problem-solving and multi-tasking (8). To test the hypothesis that middle-aged adults invest more effort than young adults, especially in resource-demanding situations, an experimental paradigm is needed which involves conditions varying in processing demands and which also includes a measure of cognitive effort. Such a paradigm can be derived from the levels-of-processing framework proposed by Craik and Lockhart (9). In their view, incoming information can be processed in different ways, which may vary from shallow to deep processing (10). Deeper analysis produces a richer and more elaborated memory trace (11), which is more resistant to forgetting.

Although this levels-of-processing framework has undergone several revisions since its initial formulation (e.g., 12), the earliest version was most influential in the area of cognitive aging. Following the levels-of-processing hypothesis, it has been suggested that older adults have a deficiency in deep, semantic processing, which may result in memory impairment (10). This hypothesis was tested by early studies in which recall and recognition by young and older adults were compared after performing incidental processing tasks (i.e., perceptual, phonological, or semantic analysis of words) and an intentional learning task (i.e., memorization of words) (White, cited in 13, 1418). The predominant pattern of results with respect to recall was that age differences were small and unreliable af-

Key words: Aging, deep processing, education, verbal learning.

Correspondence: Jelle Jolles, Brain and Behaviour Institute, Department of Psychiatry and Neuropsychology, Maastricht University, P.O. Box 616, 6200 MD Maastricht, The Netherlands.

E-mail: j.jolles@np.unimaas.nl

Received September 13, 2006; accepted in revised form February 15, 2007. 
ter shallow processing tasks and greater after deeper processing tasks (White, cited in 13, 14, 16, 17). It was suggested that deep processing is cognitively effortful and places a strain on the diminished resources of older adults (19). In contrast, when memory for words was tested by recognition, age differences after deep incidental instructions (White, cited in 13, 14, 16) and intentional learning (14-16) were much less pronounced. This suggests that the self-initiated search component of retrieval, which is presumably bypassed by recognition (19), is mainly sensitive to an age-related deficiency in deep processing.

However, the above-mentioned studies only examined the number of correctly recalled and recognized words. $\mathrm{Be}-$ cause an age-related deficiency in deep processing is presumably manifested in retrieval processes, it was considered of interest to examine reaction times (RTs) of recognition. Although the exact nature of the retrieval processes involved in recognition is still a matter of debate, the assumption that old-new responses are initiated when sufficient evidence has accumulated to justify one response or the other is accepted and incorporated into most theories $(20,21)$. The main construct to be extracted from RTs is therefore retrieval effort, the mobilization of processing resources required to retrieve items from memory (22). Most current theorists propose slower recall-like processes, often termed "recollection", as one component, and faster parallel retrieval, often termed "familiarity", as the other component, in a dual-route retrieval framework of recognition (see 23 for a review). Longer RTs would then represent less efficient mobilization of processing resources and more retrieval effort. This is in accordance with dual task paradigms in which RTs are also used as estimates of mental effort (24). Because deeper processing results in better maintenance of words in memory, deeperprocessed words are expected to require less retrieval effort than shallow-processed words. In this regard, we could test whether deeper processing leads in middleaged adults to a smaller decrease in retrieval effort than in young adults. The first purpose of the present study was therefore to examine whether deeper processing of words during encoding leads in middle-aged adults to a smaller increase in word-learning performance and a smaller decrease of RTs than in young adults.

Within the study of cognitive aging, relatively limited attention has been given to factors affecting cognitive abilities in midlife (25). Protective factors in cognitive maintenance and plasticity are important as possible mechanisms to be targeted in preventive interventions. High educational level may attenuate an age-related increase in effort investment and change in verbal learning performance, because educational experience may provide reserve capacity in the form of a more elaborate set of basic skills or cognitive strategies (26). Indeed, high educational level has been shown to attenuate age-related cognitive decline in older adults $(27,28)$. Others, however, have questioned the idea that more highly educated and more intelligent individuals show decelerated cognitive aging with respect to individuals with lower mental ability (29). A recent study (30) did show that the protective influence of education on cognitive aging is limited. This may be a general limitation, but the influence of education may also depend on the cognitive domain. An interesting issue is whether higher educational level, which stimulates language proficiency and the use of encoding and retrieval cues, compensates for the reduced benefit of deep processing in middle-aged individuals. The second purpose of the present study was therefore to examine whether age-related memory differences after performing shallow and deeper learning tasks are moderated by level of education.

Four incidental learning tasks were used, each designed to induce processing at a particular level. The first task was to decide whether words were written in lowercase or uppercase letters, which was assumed to induce shallow perceptual processing $(31,32)$. The second task was to decide whether words contained the letter " $e$ ", which was assumed to induce more elaborate orthographic/phonological processing (33). In essence, this was a search task, and the finding that RTs for words not containing the letter " $e$ " were longer than for words containing it (34) suggested that a terminating search strategy (35) was adopted, in which each letter was assessed. In the third task, participants had to speak words aloud without making a decision, which was assumed to invoke at least perceptual, orthographic and phonological processing of the whole word. Access of information concerning the meaning of a word is not necessarily involved in this task (36). The fourth task was to decide whether words referred to a living or a non-living item, which was assumed to invoke deep semantic processing $(31,37)$. Four intentional memorizing tasks were also administered. In contrast to previous studies on age differences within the levels-of-processing framework that used a between-subject design, a more powerful mixed design was used here, in which each participant received all conditions. A younger (25-35 years) group was also compared with an older middle-aged (50-60 years) group. These groups consisted of persons from the working population and were therefore less subject to differences in lifestyle associated with schooling or retirement. In addition, they were without age-related health problems with potential impact on brain function, in order to reduce any source of bias due to age-extrinsic factors.

\section{METHOD}

\section{Participants}

Eighty adults from two age groups participated in the study. The younger group consisted of 20 people of low educational level and 20 people with high level, aged between 25 and 35 [mean age: 29.0 years, standard de- 


\begin{tabular}{lccccc}
\hline & \multicolumn{2}{c}{ Young (25-35 yr) } & & \multicolumn{2}{c}{ Middle-aged (50-60 yr) } \\
\cline { 2 - 3 } & $\begin{array}{c}\text { Low educational } \\
\text { level }\end{array}$ & $\begin{array}{c}\text { High educational } \\
\text { level }\end{array}$ & & $\begin{array}{c}\text { Low educational } \\
\text { level }\end{array}$ & $\begin{array}{c}\text { High educational } \\
\text { level }\end{array}$ \\
\hline N. & 20 & 20 & & 20 & 20 \\
Age: mean (SD) & $29.9(0.64)$ & $28.1(0.57)$ & & $57.4(0.61)$ & $54.9(0.82)$ \\
Male/female ratio (n/n) & $10 / 10$ & $10 / 10$ & & $10 / 10$ & $10 / 10$ \\
Educational category: mean (SD) & $3.65(0.75)$ & $6.55(0.69)$ & & $2.3(0.66)$ & $5.35(1.33)$ \\
Vocabulary: mean (SEM) & $11.7(0.49)$ & $14.9(0.49)$ & & $12.9(0.49)$ & $15.3(0.49)$ \\
Left-/right-handedness ratio (n/n) & $17 / 3$ & $16 / 4$ & & $20 / 0$ & $19 / 1$ \\
\hline
\end{tabular}

viation $(\mathrm{SD})=2.8 \mathrm{l}$. The older middle-aged group consisted of 20 people of low educational level and 20 people with a high level, aged between 50 and 60 (mean age: 56.1 years, $\mathrm{SD}=3.4$ ). Participants were stratified for age (two age groups), education (two levels) and sex. They were recruited by advertisements in local newspapers and advertising at Maastricht University, local companies and clubs (e.g., sports, music). There was pre-selection by telephone, in order to exclude persons with health-related conditions known to interfere with normal cognitive functioning. Exclusion criteria were cerebrovascular pathologies, psychiatric disturbances, neurological disorders, dyslexia, serious medical conditions with known impact on brain function, excessive use of alcohol (>21 consumptions/week), use of psychoactive medication or drugs, clinically overt visual or auditory deficits, and previous participation in cognitive experiments. The Ethics Committee of the Department of Psychology, Maastricht University, approved the study, and participants gave their written informed consent.

Level of education was assessed by classifying formal schooling according to a system commonly used in the Netherlands (38), which is comparable to the International Standard Classification of Education (39). Educational level was scored in eight ordinal categories: 1) primary education, 2) lower vocational education, 3) intermediate secondary education, 4) intermediate vocational education, 5) higher secondary education, 6) higher vocational education, 7) higher professional education, 8) university. In many Western countries, persons between 50 and 60 are - generally - less well educated than persons between 25 and 35 . Thus, the median educational level in the population differs for the age ranges used in the present study (40). We attempted to deal with this cohort effect by adjusting the classification into low and high educational levels according to the median level in the population. A low level of education was defined in the young group as a maximum of intermediate vocational education (equivalent to a maximum of 13 years of education). A low level of education was defined in the older group as a maximum of intermediate secondary education (equivalent to a maximum of 10 years of education).

The characteristics of the sample are listed in Table 1, and show that persons with low educational level were slightly older than persons with high educational level in both the young, $F(1,38)=4.4, p<0.05$, and the old age groups, $F(1,38)=6.0, p<0.05$. Because the difference was at most 2.5 years, this was not considered to be a problem. The young and middle-aged participants did not perform differently on a 20 -item multiple-choice Dutch vocabulary test (41) measuring verbal IQ, $F(1,76)=3.1$, $p=0.09$. The vocabulary scores of highly-educated participants were higher than those for less well educated participants, $\mathrm{F}(1,76)=33.1, p<0.01$.

\section{Materials and procedure}

The procedure is described chronologically.

Incidental tasks. Four computerized tasks with 16 words were presented one after another in each task. In the first task, in which eight words were presented in uppercase and eight in lowercase, participants were asked to make a decision about the case of the letters. In the second task, participants had to indicate whether or not the words contained the letter " $e$ ". In the third task, they had to read the words aloud without making a decision. In the last task, they were asked whether the words referred to a living or a non-living item. The order in which the tasks were presented was randomized within each age group per educational level. The words used were mono- or disyllabic, varying in length between five and seven letters, and with a value of six or higher on a Dutch 7-point norm scale for imagery (42). Words were presented in the center of a computer screen (font: Arial, 50 pt.) and were white against a black background. The presentation software was programmed in E-prime (43). The four tasks involved four fixed word lists, matched for word frequency and word length. All lists contained eight living items and eight words containing the letter " $e$ ". They were carefully matched with respect to the categories from which 
the words were drawn (i.e., animals, flowers, tools, etc.) and to phonological characteristics.

Participants were seated in front of a 17" monitor at a normal viewing distance of approximately 25 inches (60 $\mathrm{cm}$ ), and responded with either their left or right index finger using two response buttons. In the three decision tasks, a right button press indicated "uppercase", "containing $e$ " and "living", respectively. In these tasks, the words were presented on the screen for a maximum of $1500 \mathrm{~ms}$, until a response was given. A fixed interval of 2000 ms between the appearance of one word and the appearance of the next was used. Participants were told to respond as quickly and accurately as possible. In the reading task, the words were presented for $1000 \mathrm{~ms}$ on the screen, with an interval of 2000 ms between the appearance of one word and the appearance of the next.

Recall and recognition of incidentally presented words. A 5-min delay was imposed, during which participants copied the Rey Complex Figure (44), which involves no verbal stimuli. After this delay, they were unexpectedly asked to recall orally as many of the words they had encountered in the four tasks as possible. Subsequently, they performed an old/new recognition task, consisting of 32 old words (8 from each incidental task) and 32 new words, presented in random order. The new words were selected using the same criteria as those that were presented in the incidental tasks (mono/disyllabic, 5-7 letters, matched for word frequency, word length, and number of living items). Participants responded with either their left or right index finger, using two response buttons to indicate whether the word had been seen before in the incidental tasks. A right button press indicated "yes", and a left button press "no". The words were presented on the screen for a maximum of $2500 \mathrm{~ms}$, until a response was given. There was a fixed interval of 3000 ms between the appearance of one word and the appearance of the next. Participants were told to respond as quickly and accurately as possible. RTs and accuracy measures were recorded.

Intentional tasks. When recognition of the incidental tasks was completed, two sustained attention tests (Mackworth Clock Test, and Continuous Performance Test $\mathrm{AX}$ ) which did not involve the learning of verbal material, were administered for about 20 min, with a break of 5 min in between. After this delay of 25 min, participants were asked to memorize a list of 16 words for subsequent recall. After presentation of the words, participants were asked to recall as many of them as possible in any order. This procedure was conducted four times with different word lists. The order in which the lists were presented was randomized within each age group per educational level. In these four tasks, the words were presented for $1000 \mathrm{~ms}$ on the screen, with an interval of $2000 \mathrm{~ms}$ between the appearance of one word and the appearance of the next. The characteristics and computerized presentation of the words were the same as in the incidental tasks.
Recall and recognition of intentionally presented words. A 5-min delay was imposed, during which the participants copied the Taylor figure (45), which involves no verbal stimuli. After this delay, they were asked to reproduce orally as many of the words they had encountered in the four intentionally presented lists as possible. Subsequently, they performed an old/new recognition task, consisting of 32 old words (8 from each intentional task) and 32 new words, presented in random order. The characteristics and computerized presentation of the words were the same as in the recognition of the incidental tasks.

\section{Design}

A cross-sectional design was used, with two age groups (young and middle-aged) and two educational levels (low and high). All participants received four incidental conditions and, because the procedure of recall and recognition had to be similar for intentional and incidental learning, they also received four parallel intentional tasks. Their mean performance on these was used as a measure of intentional learning. This yielded a $5 \times 2 \times 2$ design with type of task (case decision, "e" detection, reading, semantic decision and intentional learning) as the withingroups variable, and age group and educational level as the between-groups variables. The number of correctly recalled words, recognized words, and mean RTs for correctly and incorrectly recognized words were the dependent variables.

\section{Data analysis}

The assumptions of analysis of variance (ANOVA; homogeneity of variance and normality of the residuals) were tested for each dependent variable. Homogeneity of variance was evaluated by visual inspection of the scatter plots of the residuals against the predicted values. Normal distribution of the residuals was checked by visual inspection of the histograms and the normal probability plots. Based on this information, data transformation was not considered necessary. Full-factorial repeatedmeasures ANOVAs were used per dependent variable. A Greenhouse-Geisser correction was applied to the degrees of freedom and the significance levels if the sphericity assumption was violated. Statistically significant main effects of task type and interactions with task type were further analyzed following Fisher's least significant difference (LSD) procedure. Repeated contrast analyses were conducted in order to analyze differences between consecutive levels of processing. Simple contrast analyses were conducted in order to analyze differences between intentional learning on one hand and each incidental task on the other. Post-hoc power analyses (46) per dependent variable on the available number of participants, with a medium critical effect size of 0.25 and an alpha level of 0.05 , resulted in a power of 0.99 for all three dependent variables with respect to the within-groups effects, and 
$0.97,0.89$ and 0.81 with respect to the between-groups effects for recall, accuracy, and RTs of recognition, respectively.

\section{RESULTS}

\section{Recall}

Figure $1 \mathrm{~A}$ shows the mean numbers of correctly recalled words from each incidental task and four intentional tasks per age group. A main effect of age was found, indicating that younger individuals outperformed older individuals, $F(1,76)=22.5, p<0.01$, partial $\eta^{2}=0.23$ (means over all conditions: 2.0 and 1.3, for the young and old age groups, respectively). There was a main effect of task, $\mathrm{F}(3$, $229.1)=68.1, p<0.01$, partial $\eta^{2}=0.47$, indicating that more words were recalled as depth of processing increased (means: 0.36, 0.6, 1.8, 2.9, and 2.7 words for case decision, "e" detection, reading, semantic decision, and intentional learning tasks, respectively). Repeated contrasts were significant, except that between semantic decision and intentional learning. The simple contrasts were also significant, except that between semantic decision and intentional learning. An age-by-task interaction was found, indicating that the age-related differences in recall increased with depth of processing, $F(3,229.1)=2.7$, $p<0.05$, partial $\eta^{2}=0.035$. Only the repeated contrast case decision us " $e$ " detection, and the simple contrast case decision us intentional learning, were significant However, floor effects complicated this interaction in the shallow conditions.

A significant main effect of education was found, indicating that highly-educated people recall more words than less well educated people: $\mathrm{F}(1,76)=4.9, p<0.05$, partial $\eta^{2}=0.061$ (means are 1.5 and 1.8 words for low and high educational level, respectively). No age $\mathrm{x}$ task $\mathrm{x}$ education, education $\mathrm{x}$ age, or education $\mathrm{x}$ task interactions were found (F-values $<2.6, p$-values $>0.1$ ).

\section{Accuracy of recognition}

Figure $1 \mathrm{~B}$ shows the mean numbers of correctly recognized words from each incidental task and four intentional tasks per age group. A main effect of age was found, indicating that younger individuals outperformed older individuals, $\mathrm{F}(1,75)=8.1, p<0.01$, partial $\eta^{2}=0.1$ (means over all conditions: 5.6 and 4.9 words for the young and old age groups, respectively). There was a main effect of task, $F(3.5,263.5)=81.5, p<0.01$, partial $\eta^{2}=0.52$ (means: $3.6,3.9,6.1,6.7$, and 6.0 words for case decision, "e" detection, reading, semantic decision and intentional learning tasks, respectively). Repeated contrasts were significant, except that between case decision and " $e$ " detection. The simple contrasts were also significant, except that between reading and intentional

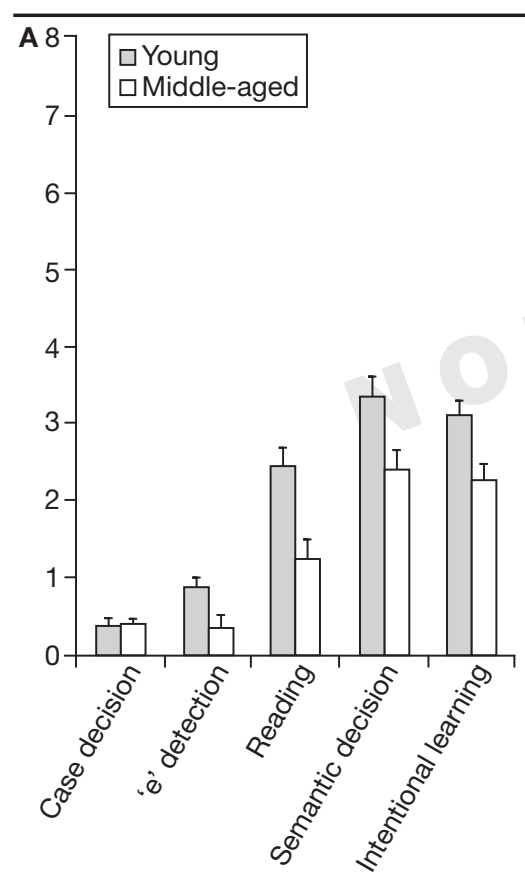

Condition

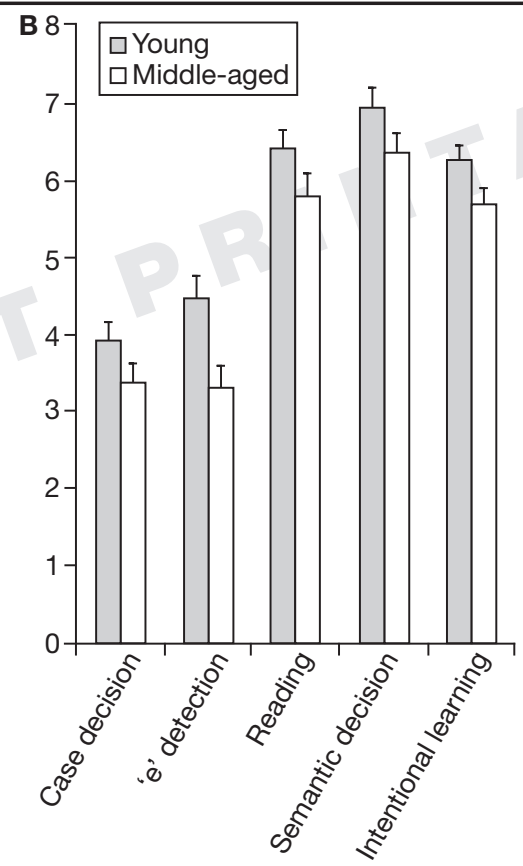

Condition

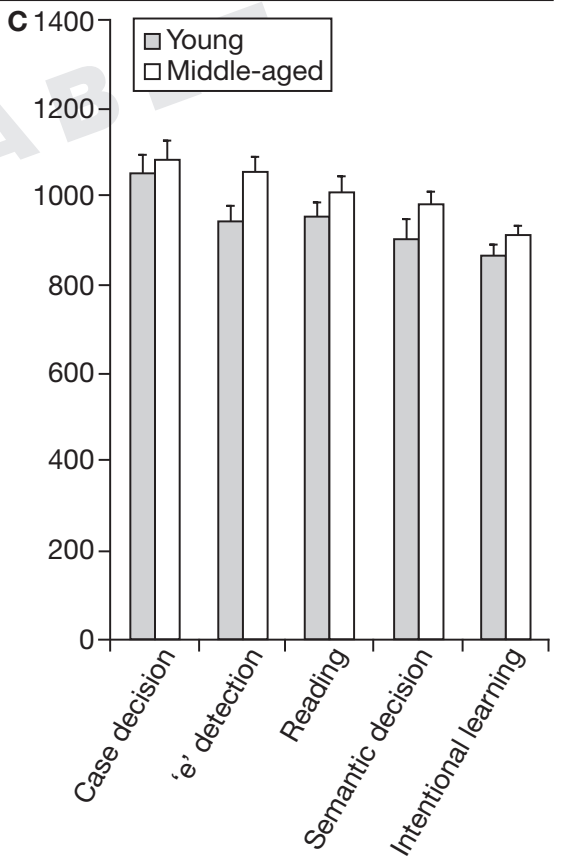

Condition

Fig. 1 - Mean accuracy on recall (A), recognition (B), and reaction times of recognition $(C)$ as a function of age and task. Error bars: standard errors of mean. 
learning. No age-by-task interaction was found, indicating that the age-related differences in recognition accuracy were equal across tasks, $\mathrm{F}(3.5,263.5)=0.74, p>0.5$.

A main effect of education was found, indicating that highly-educated people recognized more words than less well educated people: $\mathrm{F}(1,75)=5.2, p<0.05$, partial $\eta^{2}=0.065$ (means: 4.9 and 5.5 words for low and high educational level, respectively). No age $\mathrm{x}$ task $\mathrm{x}$ education, education $\mathrm{x}$ age, or education $\mathrm{x}$ task interactions were found (F-values $<2.2, p$-values $>0.06$ ).

Because recognition was tested for the incidental conditions together, the number of true negatives, i.e., correctly identified new words, could not be separated for each incidental condition. The same applied to the intentional conditions. The number of true negatives did not differ between age groups with respect to the incidental tasks, $F(1,75)=0.76, p>0.3$ (means: 24.3 and 25.4 for the young and middle-aged groups, respectively), and educational levels, $F(1,75)=0.83, p>0.3$ (means: 25.5 and 24.3 for the low and high levels, respectively). An education $x$ age interaction was not found, $F(1,75)=0.3$, $p>0.5$. The same pattern of results was found for the intentional tasks: the number of true negatives did not differ between age groups, $F(1,75)=1.3, p>0.2$ (means: 25.3 and 26.4 for the young and middle-aged groups, respectively), and educational levels, $F(1,75)=0.43, p>0.5$ (means are 26.2 and 25.6 for the low and high levels, respectively). An education $x$ age interaction was not found either, $F(1,75)=0.6, p>0.4$. On the basis of these results, we concluded that groups did not differ in their response bias, which would reduce the effectiveness of the recognition score as a measure of retention (47).

\section{Reaction times of recognition}

The RTs of correctly recognized words were shorter than those of incorrectly recognized ones (means, collapsed over conditions: 1000 and 1179 ms, respectively). However, no differences between age groups or educational levels were found.

We therefore decided to collapse the mean RTs over correctly and incorrectly recognized words, in order to obtain a more robust measure of retrieval effort. Figure $1 \mathrm{C}$ shows these mean RTs from each incidental task and four intentional tasks per age group. There was no main effect of age, $\mathrm{F}(1,75)=3.4, p=0.07$, indicating that the two age groups did not differ in RT (mean RTs over all conditions: 946 and $1006 \mathrm{~ms}$ for the young and old age groups, respectively). There was a main effect of task, $F(4,300)=15.8, p<0.01$, partial $\eta^{2}=0.17$ (means: 1065, 999, 982, 944 and 891 ms for case decision, "e" detection, reading, semantic decision tasks and intentional learning, respectively). Repeated contrasts were significant between case decision and " $e$ " detection and between semantic decision and intentional learning. All simple contrasts were significant. No age-by-task inter- action was found, indicating that the age-related differences in RT performance were equal across tasks, F(4, $300)=0.72, p>0.5$.

A main effect of education was found, indicating that highly-educated people had shorter RTs than less well educated people: $\mathrm{F}(1,75)=4.3, p<0.05$, partial $\eta^{2}=0.055$ (means: 1011 and $942 \mathrm{~ms}$, for low and high educational levels, respectively). No age $\mathrm{x}$ task $\mathrm{x}$ education, education $\mathrm{x}$ age, or education $\mathrm{x}$ task interactions were found (F-values $<1, p$-values $>0.2$ ).

\section{DISCUSSION}

The first purpose of the present study was to examine whether deeper processing of words during encoding in middle-aged adults leads to a smaller increase in wordlearning performance and a smaller decrease in retrieval effort than in young adults. A main effect of task on accuracy of recall and recognition indicated that wordlearning performance did increase after deeper processing. A major outcome of this study is that the performance increase was smaller in middle-aged adults than in young adults with respect to recall. Age differences did not differ across levels of processing in recognition. These findings are generally in accordance with previous studies, in which mainly extreme age groups were compared (White, cited in 13, 14-18). Although we observed floor effects in the shallow conditions, our results are in line with previous studies that were not complicated by floor effects (14, 17). Thus, the present study demonstrates the already smaller benefit of deep processing in middle-aged individuals. Moreover, these effects seem to be purely attributable to aging, since the participants in the present study were carefully screened for health problems, to exclude potential age-extrinsic confounders.

To our knowledge, the present study is the first that also examined RTs of recognition, which enabled us to examine retrieval mechanisms. The main effect of task on RTs of recognition indicated that retrieval effort decreased with depth of processing. The absence of an age-by-task interaction demonstrated that this decrease in retrieval effort was not smaller in middle-aged adults. It has been shown that aging affects recollection more than familiarity (23). The present main effect of age on RTs most probably reflects age-related slowing in recollection processes and of non-decision components of processing, such as encoding and response execution. The absence of an age-by-task interaction suggests that this age-related slowing does not depend on level of processing.

The general pattern of results thus suggests that the reduced benefit of deep processing in middle age is confined to the self-initiated search component of retrieval, which is required in recall but not in recognition. A major difference between recall and recognition is the amount of environmental support offered (19), that is, the words themselves are reinstated on a recognition test, which di- 
minishes the need for a constraining self-initiated search of the memory store. The present findings are therefore in line with many studies demonstrating smaller age differences when contextual or cognitive support is provided (see 48 for a review). When extended to daily life, this suggests that, in more resource-demanding situations, in which information has to be processed both quickly and thoroughly and when no retrieval cues are available, adults already show cognitive vulnerability in middle age. When middle-aged adults are exposed frequently or longer to such cognitively challenging and stressful situations - for example, in a professional context - their decreased processing capacities may lead to exhaustion of resources, in turn resulting in cognitive complaints. Persistent strain on diminished cognitive resources may even lead to more pathological conditions, such as mood problems, mental fatigue, neuro-energetic problems, and dysthymia, or 'burn-out', which are common in the middle-aged working population (49-51). Further longitudinal research may unravel the mechanisms proposed in this line of reasoning.

The second purpose of the present study was to examine whether a high educational level compensates for the reduced benefit of deep processing. More highly educated persons had consistently shorter RTs and higher accuracy levels than persons with a lower educational level. However, education did not interact with age or task on either of the dependent variables. This suggests that education is not a moderating factor of age-related changes in verbal learning manipulated by levels of processing, at least not over the present age-trajectory. This may be explained by one of the proposed mechanisms for the hypothesized protective effect of education. This mechanism assumes that education serves as a marker for other conditions related to socio-economic status, such as health status (52), which is also known to influence age-related cognitive change (53). The protective effect of education may therefore not have been demonstrated in the present study, because all our participants were screened for health problems to exclude potential age-extrinsic confounders.

It should be noted that, before the 1960s, many people did not finish or continue their schooling, mostly for reasons other than their intellectual capacity (54). As a consequence, there is a risk of underestimating the cognitive differences associated with age in poorly educated people. By including a young and a middle-aged group, which yielded fewer cohort differences than a comparison between a young and an old group, and by defining the low and high levels of educational achievement differently for young and middle-aged persons, this risk was minimized in the current study.

Because the issue of the interaction between age and education has seldom been addressed by experimental studies, it is not yet clear in which cognitive domains education may have a protective effect and what the de- terminants of such an effect are. The few previous studies mainly found smaller age differences in highly-educated persons in verbal memory $(55,56)$, visual attention (56), and some subtests of the Wechsler Adult Intelligence Scale (57). In a recent study, we found that education attenuates age-related differences in verbal learning, but that its protective power reaches a limit when task demands were increased by the combination of the presence of irrelevant speech and a shorter inter-stimulus interval (58). Since task demands were very high in the present mod$e l$, in that words were only presented once and in rapid conditions (in contrast to frequently-used multi-trial verbal learning tasks), the absence of interactions between education, age and level-of-processing may again point at a limit of the protective power of education. Future research should define more precisely those tasks, task conditions and individual characteristics (such as health status) that allow older persons with a high educational level to compensate for negative age effects.

\section{REFERENCES}

1. Rabbitt P. Does it all go together when it goes? The Nineteenth Bartlett Memorial Lecture. Q J Exp Psychol A 1993; 46: 385434.

2. Houx PJ, Vreeling FW, Jolles J. Rigorous health screening reduces age effect on memory scanning task. Brain Cogn 1991; 15: 24660.

3. Houx PJ, Jolles J, Vreeling FW. Stroop interference: aging effects assessed with the Stroop Color-Word Test. Exp Aging Res 1993; 19: 209-24.

4. Houx PJ, Jolles J. Age-related decline of psychomotor speed: effects of age, brain health, sex, and education. Percept Mot Skills 1993; 76: 195-211.

5. Ponds RW, Commissaris KJ, Jolles J. Prevalence and covariates of subjective forgetfulness in a normal population in The Netherlands. Int J Aging Hum Dev 1997; 45: 207-21.

6. Jonker C, Geerlings MI, Schmand B. Are memory complaints predictive for dementia? A review of clinical and population-based studies. Int J Geriatr Psychiatry 2000; 15: 983-91.

7. Ponds RW, van Boxtel MP, Jolles J. Age-related changes in subjective cognitive functioning. Educat Gerontol 2000; 26: 7-81.

8. Schooler C. The workplace environment: measurement, psychological effects, and basic issues. In Friedman SL and Wachs TD, eds. Measuring environment across the lifespan. Washington, DC: American Psychological Society, 1999: 229-246.

9. Craik FIM, Lockhart RS. Levels of processing: a framework for memory research. J Verbal Learn Verbal Behav 1972; 11: 67184.

10. Burke DM, Light LL. Memory and aging: the role of retrieval processes. Psychol Bull 1981; 90: 513-46.

11. Craik FIM, Tulving E. Depth of processing and the retention of words in episodic memory. J Exp Psychol Gen 1975; 104: 268-94.

12. Craik FIM. Levels of processing: past, present.... and future? Memory 2002; 10: 305-18.

13. Craik FIM. Age differences in human memory. In Birren JE and Schaie KW, Eds. Handbook of the Psychology of Aging. New York: Van Nostrand Reinhold, 1977.

14. Erber J, Herman TG, Botwinick J. Age differences in memory as 
a function of depth of processing. Exp Aging Res 1980; 6: 341-8.

15. Mason SE. Effects of orienting tasks on the recall and recognition performance of subjects differing in age. Dev Psychol 1979; 15: 467-9.

16. Rankin JL, Hyland TP. The effects of orienting tasks on adult age differences in recall and recognition. Exp Aging Res 1983; 9: 159-64.

17. Eysenck MW. Age differences in incidental learning. Dev Psychol 1974; 10: 936-41.

18. Zelinski EM, Walsh DA, Thompson LW. Orienting task effects on EDR and free recall in three age groups. J Gerontol 1978; 33: 239-45.

19. Kausler DH. Learning and memory in normal aging. San Diego, CA: Academic Press, 1

20. Diller DE, Nobel PA, Shiffrin RM. An ARC-REM model for accuracy and response time in recognition and recall. J Exp Psychol Learn Mem Cogn 2001; 27: 414-35.

21. Ratcliff R, Smith PL. A comparison of sequential sampling models for two-choice reaction time. Psychol Rev 2004; 111: 333-67.

22. Rugg MD, Allan K, Birch CS. Electrophysiological evidence for the modulation of retrieval orientation by depth of study processing. J Cogn Neurosci 2000; 12: 664-78.

23. Yonelinas, AP. The nature of recollection and familiarity: a review of 30 years of research. J Mem Lang 2002; 46: 441-517.

24. Karatekin C, Couperus J, Marcus D. Attention allocation in the dual-task paradigm as measured through behavioral and psychophysiological responses. Psychophysiology 2004; 41: 175-85.

25. Willis SL, Schaie KW. Cognitive trajectories in midlife and cognitive functioning in old age. In Willis SL, Martin M, Eds. Middle Adulthood: A Lifespan Perspective. Thousand Oaks: Sage Publications, 2005: 243-277.

26. Stern Y. What is cognitive reserve? Theory and research application of the reserve concept. J Int Neuropsych Soc 2002; 8 : 448-60.

27. Bosma H, van Boxtel MP, Ponds R, Houx P, Jolles J. Education and age-related cognitive decline: the contribution of mental workload. Educat Gerontol 2003; 29: 1-9.

28. Anstey K, Christensen H. Education, activity, health, blood pressure and apolipoprotein $\mathrm{E}$ as predictors of cognitive change in old age: a review. Gerontology 2000; 46: 163-77.

29. Rabbitt $P$, Chetwynd A, Mclnnes L. Do clever brains age more slowly? Further exploration of a nun result. Brit J Psychol 2003; 94: 63-71.

30. Christensen H, Anstey KJ, Parslow RA, Maller J, Mackinnon A, Sachdev $\mathrm{P}$. The brain reserve hypothesis, brain atrophy and aging. Gerontology 2007; 53: 82-95.

31. Daselaar SM, Veltman DJ, Rombouts SA, Raaijmakers JG, Jonker C. Deep processing activates the medial temporal lobe in young but not in old adults. Neurobiol Aging 2003; 24: 1005-11.

32. Bentin S, Mouchetant-Rostaing Y, Giard MH, Echallier JF, Pernier J. ERP manifestations of processing printed words at different psycholinguistic levels: time course and scalp distribution. J Cogn Neurosc 1999; 11: 235-60.

33. Proverbio AM, Vecchi L, Zani A. From orthography to phonetics: ERP measures of grapheme-to-phoneme conversion mechanisms in reading. J Cogn Neurosc 2004; 16: 301-17.

34. Meijer WA, de Groot RHM, van Gerven PWM, van Boxtel MPJ, Jolles J. Level of processing and reaction time in young and middle-aged adults and the effect of education, submitted.

35. Schneider W, Shiffrin RM. Controlled and automatic processing:
1. Detection, search and attention. Psychol Rev 1977; 84: 1-66.

36. Seidenberg MS, McClelland JL. A distributed, developmental model of word recognition and naming. Psychol Rev 1989; 96: 523-68.

37. Tisserand DJ, McIntosh AR, van der Veen FM, Backes WH, Jolles J. Age-related reorganization of encoding networks directly influences subsequent recognition memory. Cognitive Brain Res 2005; 25: 8-18.

38. de Bie SE. Standaardvragen 1987: Voorstellen voor uniformering van vraagstellingen naar achtergrondkernmerken en interviews [Standard questions 1987: Proposal for uniformisation of questions regarding background variables and interviews], $2^{\text {nd }}$ ed. Leiden: Leiden University Press, 1987.

39. International Standard Classification of Education (ISCED). Paris: UNESCO, 1976.

40. Mares AMHM. Jaarboek onderwijs in cijfers [Yearbook education in numbers]. Centraal Bureau voor de Statistiek, 2004.

41. Luteijn F, van der Ploeg FAE. Handleiding Groninger Intelligentietest (GIT) [Manual Groningen Intelligence Test]. Lisse: Swets and Zeitlinger, 1983.

42. Van Loon-Vervoorn, WA. Voorstelbaarheidswaarden van Nederlandse woorden: 4600 substantieven, 1000 verba en 500 adjectieven [Imagery values of Dutch words: 400 nouns, 1000 verbs and 500 adjectives]. Lisse: Swets \& Zeitlinger, 1985.

43. Schneider W, Eschman A, Zuccolotto A, Eds. E-prime User's Guide. Vol. 1.0. Pittsburgh: Psychology Software Tools, 2002.

44. Rey A. L'examen psychologique dans le cas d'encéphalopathie traumatique [Psychological examination of traumatic encephalopathy]. Archives de Psychologie 1941; 28: 286-340.

45. Taylor DC. Affective disorders in epilepsies: a neuropsychiatric review. Behav Neurol 1989; 2: 49-68.

46. Buchner A, Faul F, Erdfelder E. GPOWER: A priori-, post hoc-, and compromise power analyses for the Macintosh. Bonn: Bonn University, 1992.

47. Harris ME, Ivnik RJ, Smith GE. Mayo's Older Americans Normative Studies: expanded AVLT Recognition Trial norms for ages 57 to 98. J Clin Exp Neuropsyc 2002; 24: 214-20.

48. Backman L. Varieties of memory compensation by older adults in episodic remembering. In Poon LW, Rubin DC, Wilson BA, Eds. Everyday cognition in adulthood and late life. Cambridge: Cambridge University Press, 1989: 509-45.

49. Lindblom KM, Linton SJ, Fedeli C, Bryngelsson. Burn-out in the working population: relations to psychosocial work factors. Int $\mathrm{J}$ Behav Med 2006; 13: 51-9.

50. Schwarz R, Krauss O, Hinz A. Fatigue in the general population. Onkologie 2003; 26: 140-4.

51. Sluiter JK, de Kroon EM, Meijman TF, Frings-Desen, MH. Need for recovery from work-related fatigue and its role in the development and prediction of subjective health complaints. Occup Environ Med 2003; 60 Suppl 1: 62-70.

52. Lasheras C, Patterson AM, Casado C, Fernandez S. Effects of education on the quality of life, diet, and cardiovascular risk factors in an elderly Spanish community population. Exp Aging Res 2001; 27: 257-70.

53. van Hooren SA, Valentijn SA, Bosma H, Ponds RWHM, van Boxtel MP, Jolles J. Relation between health status and cognitive functioning: a 6-year follow-up of the Maastricht Aging Study. J Gerontol B: Psychol 2005; 60: 57-60.

54. Jolles J, Houx P, van Boxtel MP, Ponds RWHM, Eds. Maastricht Aging Study: determinants of cognitive aging. Maastricht: Neuropsych Publishers, 1995.

55. Ardila A, Ostrosky-Solis F, Rosselli M, Gomez C. Age-related cog- 
nitive decline during normal aging: the complex effect of education. Arch Clin Neuropsych 2000; 15: 495-513.

56. Capitani E, Barbarotto R, Laiacona M. Does education influence the age-related cognitive decline? A further inquiry. Dev Neuropsychol 1996; 12: 231-40.

57. Heaton RK, Grant I, Matthews CG. Differences in neuropsychological test performance associated with age, education, and sex. In Grant I, Adams KM, Eds. Neuropsychological assessment of neuropsychiatric disorders. New York: Oxford University Press, 1986: 100-20.

58. Meijer WA, de Groot RHM, van Gerven PWM, van Boxtel MP, Jolles J. Verbal learning and aging: combined effects of irrelevant speech, interstimulus interval, and education. J Gerontol B: Psychol 2006; 61: 285-94. 